\title{
Poor intestinal permeability in mildly stunted Nepali children: associations with weaning practices and Giardia lamblia infection
}

\author{
Rie Goto ${ }^{1}$, Catherine Panter-Brick ${ }^{1}$, Christine A. Northrop-Clewes ${ }^{2}$, Renu Manahdhar ${ }^{3}$ and \\ Nhuchhe R. Tuladhar ${ }^{3}$ \\ ${ }^{1}$ Department of Anthropology, University of Durham, Durham, UK \\ ${ }^{2}$ Northern Ireland Centre for Diet and Health, University of Ulster, Coleraine, UK \\ ${ }^{3}$ Department of Clinical Microbiology, Tribhuvan University, Kathmandu, Nepal
}

(Received 12 July 2001 - Revised 15 February 2002 - Accepted 2 March 2002)

\begin{abstract}
Studies in the Gambia, using the lactulose-mannitol dual-sugar intestinal permeability test (lactulose:mannitol ratio) as a non-invasive way of investigating mucosal damage, have shown that food malabsorption is significantly associated with early growth retardation. In this cross-sectional study, 210 poor urban Nepali children, 0-60 months old, were recruited and measured for height or length and weight, 167 were examined for intestinal permeability and 173 for parasite infection. Weaning and morbidity data were collected from 172 caretakers. Children were mildly stunted (mean height-for-age z-score -1.45) and underweight (mean weight-for-age $\mathrm{z}$-score -1.62$)$. The lactulose:mannitol ratio $(0 \cdot 26)$ was poorer than that of UK children $(0 \cdot 12)$, but similar to that found in Bengali children of the same age $(0 \cdot 24)$. Two stages of weaning, the onset supplementary feeding (6 months) and the cessation of breast-feeding (23 months), were shown to have differential impact. In children currently breast-feeding, the duration of supplementation was negatively related to lactose $(P<0.001)$ and lactose:lactulose values $(P<0 \cdot 0001)$, indicating lactose maldigestion. In children who had ceased breast-feeding, a longer period of lactation was associated with poorer intestinal permeability $(P=0.031)$, and poorer height-for-age $(P=0.024)$, which was an unexpected result. No significant relationships were found between intestinal permeability and growth, or with morbidity and helminth infection, except in children with Giardia lamblia who had worse lactulose:mannitol ratios than those without $(0.43 v .0 .25$ respectively, $P=0.014)$. It is likely that insults to the gut (e.g. Giardia) and challenges to the immune system (weaning) have a different impact in early and late infancy.
\end{abstract}

Breast-feeding: Lactose digestion: Growth: Malnutrition: Malabsorption: Diarrhoea

Poor growth status is an indicator of inappropriate living conditions and a poor environment (Tanner, 1986; Panter-Brick, 1998). In Nepal, children have been reported to have a high prevalence of growth retardation, in both rural areas (Costello, 1989; Panter-Brick, 1997) and among the urban poor (Panter-Brick et al. 1996; Moffat, 1998). Assessment of growth status among 6-36-monthold Nepali children has shown that $49 \%$ are underweight and $64 \%$ are stunted (Nepal Nations Multiple Indicator Surveillance, 1995; cited in UNICEF, 1996). In infancy, growth faltering is evident from 6 months (Costello, 1989; Moffat, 1998).

Most studies relate growth faltering to either food intake or infection. Lunn (2000), however, suggested that food malabsorption is a significant cause of malnutrition, resulting from abnormal function of the small intestinal mucosa. He outlined two possible mechanisms leading to undernutrition. First, following infection by dietary pathogens, possibly from unhygienic food preparation or storage, the villi in small intestinal mucosa are damaged and lose the vulnerable disaccharide lactase, leading to maldigestion of lactose and probably other nutrients. Second, the barrier function in the small intestinal mucosa is compromised by pathogens, allowing translocation of macromolecules, resulting in mucosal inflammatory and immune reactions, associated with impaired growth of children. Mucosal function can be assessed using the dual-sugar intestinal permeability test, which is used in clinical investigation

\footnotetext{
Abbreviations: HAZ, height-for-age Z-score; L:M, lactulose:mannitol; WAZ, weight-for-age z-score.

* Corresponding author: Dr Catherine Panter-Brick, fax +44 191374 7527, email Catherine.Panter-Brick@durham.ac.uk
} 
of small bowel diseases (Lunn et al. 1991), but is also valuable as a non-invasive test of gut function at community level.

The relationship between poor intestinal permeability and child growth was previously demonstrated in Gambian infants, where growth faltering was reported at about 3-4 months of age, following the introduction of supplementary foods (Lunn et al. 1991). In addition, mucosal damage may severely affect lactase activity (Northrop-Clewes et al. 1997). Lactose is the major carbohydrate in breast-milk, and thus expected to contribute to infant linear growth. Metabolism of lactose is dependent on the presence of the enzyme lactase, and lactase in the small intestine is particularly vulnerable to villi damage. The association between growth and gut damage is potentially of great importance when determining the mechanisms underlying child malnutrition and ill-health in less developed countries. It is therefore important to test whether such associations hold in other populations where unsanitary conditions and growth stunting are extremely common problems.

The timing of weaning, beginning with the introduction of supplementary foods, is a particularly important point in the child's development as diarrhoeal pathogens (e.g. E. coli, rotavirus, dysentery bacillus) in contaminated food, and soil-water-transmitted parasites are introduced and may damage the small intestinal mucosa. Indeed, in Guatemala, Goto et al. (1999) found that early weaning (as cessation of breast-feeding) worsened intestinal permeability values for infants $0-11$ months of age. In countries such as Nepal, children are usually breast-fed for periods of 2-3 years (Panter-Brick, 1992; Moffat, 2001); no studies have yet investigated the impact of late cessation of breast-feeding on gut function. However, weaning is really two different events: the introduction of supplementary foods and the cessation of breast-feeding (Almedom, 1991). We hypothesise that these two events (weaning stages 1 and 2; Fig. 1) will have a different impact on child health.

The present cross-sectional study examined the relationship between intestinal permeability, growth status, weaning practices, parasite infection and reported morbidity in children 0-60-months-old. It focused on children in poor urban squatter areas in Nepal, who live in poor sanitation and socio-economic conditions.

\section{Methods}

Samples

Fieldwork was conducted from September 1999 to April 2000 in two urban areas in Kathmandu, the capital of Nepal. Both sites are squatter settlements (illegally occupied), located near polluted rivers. The people use the river for domestic activities such as washing and travelling (there is pumped water for drinking). One site is more easily flooded by the river, being situated lower down the river bank. A house-to-house demographic survey was undertaken, reaching $95 \%$ of all households: a total of 315 households and 1411 people were surveyed in the two communities.

Anthropometric measurements were undertaken on all children aged 0-60 months in the community ( $n$ 210, ninety-eight boys and 112 girls). Parasitic infections were tested for in 173 children and 172 morbidity reports were completed (the other thirty-seven children either moved out of the community or did not give a faecal sample). Urine samples were obtained for testing intestinal permeability from 167 children. In terms of ethnic and caste composition, over half the children were of TibetoBurmese origin, $24 \%$ were Indo-Aryan high caste and $16 \%$ were Indo-Aryan low caste.

\section{Measures}

Weight (with minimum clothing) and height or length (for children over or under 24 months respectively) were measured following standard techniques (Lohman et al. 1988), using portable equipment (stadiometer $0.1 \mathrm{~cm}$ precision; length board $0.5 \mathrm{~cm}$ precision; electronic scales $0.1 \mathrm{~kg}$ precision; electric baby scale, $0.01 \mathrm{~kg}$ precision).

For the intestinal permeability test, children were given $400 \mathrm{mg}$ lactulose and $100 \mathrm{mg}$ mannitol dissolved in $2 \mathrm{ml}$ water/kg body weight, $2 \mathrm{~h}$ after breakfast (the children then abstained for $1 \mathrm{~h}$ from eating foods, but not from breast-feeding). Five hours later, urine was collected in urine bags (U-bag Urine Specimen Collector Pediatric; Hollister Ltd, Wokingham, Berks., UK), and a few drops of a bacteriostat (chlorhexidine gluconate, $200 \mathrm{ml} / \mathrm{l}$ water) were added. Total urine volume was recorded and after mixing, two $1 \mathrm{ml}$ samples were taken. The samples were frozen at $-20^{\circ} \mathrm{C}$ at the local hospital (Tribhuvan University

(Weaning stage 1)

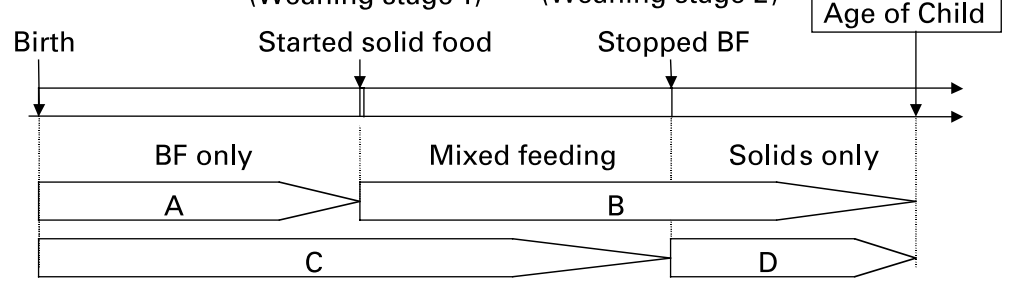

Fig. 1. Variables characterising weaning practices. BF, breast-feeding; $A$, duration of exclusive BF; $B$, duration of supplementation; $C$, time until stopped BF; D, time on solids only. 
Teaching Hospital) in Kathmandu until shipment to the UK. The samples were analysed for mannitol, lactose and lactulose by enzymatic assay (Lunn et al. 1989; Northrop et al. 1990; Blood et al. 1991; Lunn \& Northrop-Clewes, 1992) using a centrifugal spectrophotometer (Cobas Fara, Roche, Switzerland) at the Northern Ireland Centre for Diet and Health, University of Ulster.

Stool samples for the examination of parasite infection were collected by the mothers or other caretakers, using a standard procedure familiar to the Nepali: mothers inserted a stick at several places in the excreted faeces, and the faeces collected were put into a specimen case and sealed. Samples were brought daily to the Clinical Microbiology Department in the Tribhuvan University Teaching Hospital, Kathmandu, and analysed for Ascaris lumbricoides, Trichuris trichuria, Giardia lamblia, hookworm and tapeworm using standard microscopy techniques.

Interviews with the caretakers were conducted to ascertain birth date, weaning practices and child morbidity in the previous day and the preceding $7 \mathrm{~d}$. In urban Nepal, birth dates are accurately known and given in years, months, and days, with reference to the Nepali calendar. Questions on weaning practices focused on whether the child was given breast-milk, solid food, or both, and the timing of first supplementation of solid foods (pito, a gruel with lentil beans and rice, or bhat, a cooked rice) and of breast-feeding cessation. For morbidity, openended questions were asked regarding whether or not the child was ill yesterday or in the preceding $7 \mathrm{~d}$ (following Kroeger, 1983; Ross \& Vaughan, 1986). If the child was ill, there were further questions regarding the nature of the illness according to common descriptive terms: pakhala (diarrhoea), khoki (cough), ruga (cold or flu), jwaro (fever), tawko dukhey (headache), pet dukhye (stomach pain), wakwaki (nausea), bomi (vomiting), juka (worm infection) and dadura (measles) (see Gartoulla, 1998). Katz et al. (1998) found a good agreement between $7 \mathrm{~d}$ maternal report and medical examinations of child morbidity in rural Nepal.

Ethical clearance for the study was given by the University of Durham Ethics Committee in the UK and by Tribhuvan University in Nepal.

\section{Statistical analyses}

Good reliability $(R)$ for weight and height or length measurements was confirmed from a data set of repeated measurements on the same children (as recommended by Ulijaszek \& Kerr, 1999). Growth status was characterised by two variables, height-for-age and weight-for-age zscores. The z-scores (standard deviations from the median of the National Center for Health Statistics reference growth curve) were calculated using the computer software EPI-NUT in EPI-INFO (version 6.03, 1996; Center of Disease Control and Prevention, Atlanta, GA, USA).

Intestinal permeability was expressed as the ratio of the sugars lactulose:mannitol (L:M), in urine. Values for lactulose and mannitol excretion were accepted if they were within the range of expected recovery rates ((urine excretion of sugar/actual intake of sugar) $\times 100$ ). The percentage recovery rate for lactulose was $0.02-15.00$ and for mannitol 0.5-15.00. Only eleven values were excluded. Variables such as lactose (related to maldigestion) and creatinine (a proxy for urinary function) were also examined. The urinary lactose:lactulose ratio, a method for estimating lactose maldigestion was validated by Noone et al. (1986) and greater than above 0.4 was taken to indicate significant lactose maldigestion (Northrop-Clewes et al. 1997).

Intestinal permeability ratios and lactose values were converted to natural logarithm to normalise the data distribution (after the Kolmolgorov-Smirnoff statistic indicated significant skewness). The geometric mean (i.e. the anti$\log$ of mean $\log \mathrm{L}: \mathrm{M}$ ratio) was used for the purposes of comparison with previous studies. As a measure of variance, a value termed the geometric standard error (defined as (antilog (mean + standard error of logged values) geometric mean)) was also calculated. The published norm for healthy UK children (Lunn et al. 1991), geometric mean 0.12 (corresponding to a $\log \mathrm{L}: \mathrm{M}$ ratio of $-2 \cdot 12$ ), was taken to demarcate between poor and good intestinal permeability; a high L:M ratio indicates poorer gut function.

Weaning practices were coded as four variables: (A) duration of exclusive breast-feeding; (B) duration of food supplementation; (C) time until stopped breast-feeding; and (D) time on solids only (Fig. 1). Of particular interest is stage 1 (introduction of solid foods, indicated by variables A and B) and stage 2 (cessation of breast-feeding, variables $\mathrm{C}$ and $\mathrm{D}$ ) characterising the process of weaning.

Parasite infestation was recorded and coded as presence or absence of any parasite in stool samples. Morbidity data were coded as children who were ill $v$. not, and children who had diarrhoea $v$. those that did not, both in the previous day and the preceding $7 \mathrm{~d}$.

Stepwise multiple and logistic regression analyses were used to explore relationships between growth status, intestinal permeability, weaning variables, parasite infestation, morbidity and children's characteristics such as age, sex, ethnicity/caste (Tibeto-Burmese $v$. Indo-Aryan high or low caste), and squatter location (two sites). Post-hoc tests were used to evaluate differences between subgroups of children. Using the Statistical Package for the Social Sciences (SPSS, version 10.0; Chicago, IL, USA), $P<0.05$ was accepted as the level of significance.

\section{Results \\ Growth status}

Children were mildly stunted (mean height-for-age z-score (HAZ) -1.45 , SD 1.16) and underweight (mean weightfor-age $\mathrm{z}$-score (WAZ) - 1.62, SD 0.83; Table 1). There were a high proportion of children with $\mathrm{Z}$-scores $<-2$ (37 and $33 \%$ for HAZ and WAZ respectively). HAZ and WAZ values worsened with age, despite the age correction incorporated in the Z-scores: 0-12-month-old children averaged -0.50 and -0.67 for HAZ and WAZ respectively, while 12-24-month-old children averaged -1.51 
Table 1. Characteristics of Nepali squatter children (Mean values, standard deviations and ranges)

\begin{tabular}{lcccr}
\hline Variables & $n$ & Mean & SD & \multicolumn{1}{c}{ Range } \\
\hline Age (months) & 210 & 45.19 & 10.96 & $0.30-59.93$ \\
Growth status & & & & \\
$\quad$ HAZ & 199 & -1.45 & 1.16 & $-3.43-2.83$ \\
$\quad$ WAZ & 210 & -1.62 & 0.83 & $-3.15-1.06$ \\
$\begin{array}{l}\text { Intestinal permeability } \\
\quad\end{array}$ & 158 & $0.26^{*}$ & $0.21 \dagger$ & $0.04-1.71$ \\
$\quad$ Lactose & 168 & $0.16^{*}$ & $0.15 \dagger$ & $0.004-3.13$ \\
Lactose:Lactulose ratio & 157 & $0.31^{*}$ & $0.26 \dagger$ & $0.01-7.84$ \\
\hline
\end{tabular}

HAZ, height-for-age z-score; WAZ, weight-for-age z-score; L:M, lactulose: mannitol.

* Geometric mean values.

†SEM defined as: (antilog (mean + SE of logged values) - geometric mean).

for both variables (post-hoc test $P<0.0001$ ), with mean values showing no improvement after age 2 years.

Age alone made a strong impact on HAZ $\left(R^{2} 16 \%\right.$, $P<0.0001$ ), while both age and ethnicity had an impact on WAZ $\left(R^{2} 14 \%, P<0.0001\right.$ and $P=0.006$ respectively). Tibeto-Burmese children achieved better growth status than the low caste children of Indo-Aryan origin (posthoc test, $P=0.032$ for WAZ), especially after 18 months given a strong age and ethnicity interaction $(P=0.003)$. There were no detectable sex differences.

\section{Intestinal permeability ratio and lactose}

Most children (92\%) had poorer L:M ratios relative to the
UK norm of $0 \cdot 12$ (Table 2). The geometric mean was similar to that of Bengali children (L:M ratio of 0.27 for Nepal and 0.24 for Bangladesh, Table 2). The actual raw data for L:M ratio show a wide range of values (Fig. 2), all within the range of acceptable recovery rates. Child age, sex, ethnicity/caste and location had no impact on L:M ratios.

One half of children (47\%) showed low lactase activity (lactose:lactulose ratios $>0 \cdot 4$ ). Lactose values and lactose: lactulose ratios decreased with age $\left(\mathrm{R}^{2} 28 \%, P<0.0001\right)$; sex, ethnicity and location had no impact. Lactose and lactose:lactulose ratios showed no associations with L:M ratio. Breast-fed children had significantly higher urinary lactose concentrations and lactose:lactulose ratios than non-breast-fed counterparts (lactose 172.5 and $44.5 \mathrm{mg} / \mathrm{l}$; lactose:lactulose ratios 2.76 and 0.31 respectively) $(P<0.0001$, corrected for infant age $)$, but similar intestinal permeability values $(0.23$ and 0.28 respectively).

\section{Parasite infection}

Parasite infection was detected in $54 \%$ of the 173 children whose stools were examined. Ascaris lumbricoides (roundworm) was most common (59\%) followed by Trichuris trichiuria (whipworm) (37\%), Giardia lamblia (Giardia) (14\%), hookworm (9\%), and H. nana (tapeworm) (7\%). Child age and location were significant predictors of parasite infection in a logistic regression $\left(R^{2} 20 \%, P<0.0001\right.$ and $P=0.002$ respectively): parasite infection was most common for older children and in the location most easily flooded by river water.

Children with Giardia showed significantly worse L:M

Table 2. Values of intestinal permeability from the literature

\begin{tabular}{|c|c|c|c|}
\hline Location and sample & Growth and illness status & Geometric mean L:M ratio & Reference \\
\hline \multicolumn{4}{|l|}{ UK } \\
\hline $\begin{array}{l}\text { 3-15-months-old } \\
\quad(n 60)\end{array}$ & Healthy & $0.12(\text { SEM } 0.02)^{*}$ & Lunn et al. (1991) \\
\hline \multicolumn{4}{|l|}{ Rural Bangladesh } \\
\hline $\begin{array}{l}2-5 \text { years-old } \\
(n \text { 100) }\end{array}$ & $\begin{array}{l}\text { HAZ }-3.00( \pm \text { SD } 1.32) \\
\text { WAZ - } 2.70( \pm \text { SD } 0.74)\end{array}$ & 0.24 & Northrop-Clewes et al. (2001) \\
\hline \multicolumn{4}{|l|}{ 2-5-years-old } \\
\hline$(n 352)$ & Healthy & $0.23(95 \% \mathrm{Cl} 0.22,0.24)$ & Rousham et al. (1998) \\
\hline$(n 25)$ & III with diarrhoea & $0.32(95 \% \mathrm{Cl} 0.24,0.43)$ & \\
\hline \multicolumn{4}{|l|}{ Nepal, urban squatter } \\
\hline (n 167) & $\begin{array}{l}\text { HAZ - } 1.45 \text { (SD 1.16) } \\
\text { WAZ - } 1.62(\text { SD } 0.83)\end{array}$ & $0.26(\text { SEM } 0.213)^{*}$ & Present study \\
\hline \multicolumn{4}{|l|}{ The Gambia } \\
\hline $\begin{array}{l}\text { 3-15-months-old } \\
\quad(n 119, \text { total of } 922 \text { tests })\end{array}$ & Healthy & $0.38(\text { SEM } 0.010)^{*}$ & Lunn et al. (1991) \\
\hline $0-18$-months-old & & & Behrens et al. (1987) \\
\hline$(n 60)$ & WAZ > $80 \% \dagger$ & $0.42( \pm 2 \operatorname{sD} 0.2-1.4)$ & \\
\hline (n 27) & WAZ < 60\%† & $1.30( \pm 2 \mathrm{SD} 0.2-13)$ & \\
\hline$(n 47)$ & III with diarrhoea & $1 \cdot 30( \pm 2$ SD $0.2-10 \cdot 4)$ & \\
\hline \multicolumn{4}{|l|}{ Guatemala } \\
\hline $0-11$-months-old & & & Goto et al. (1999) \\
\hline$(n 200)$ & No diarrhoea & $\ddagger$ & \\
\hline$(n 10)$ & With diarrhoea & $\ddagger$ & \\
\hline
\end{tabular}

L:M, lactulose:mannitol; HAZ, height-for-age z-score; WAZ, weight-for-age z-score.

* SEM defined as: (antilog (mean + SE of logged values) - geometric mean.)

†Percentage weight-for-age z-score of the National Center for Health Statistics median (Hamill, 1977).

$¥$ Median values for L:M ratios ( 0.05 for children with diarrhoea, 0.09 for children without) but no geometric means were given in the Guatemala study. In our study of Nepal, the corresponding median value for children of the same age (0-11 months-old, $n 20)$ was $0 \cdot 21$. 


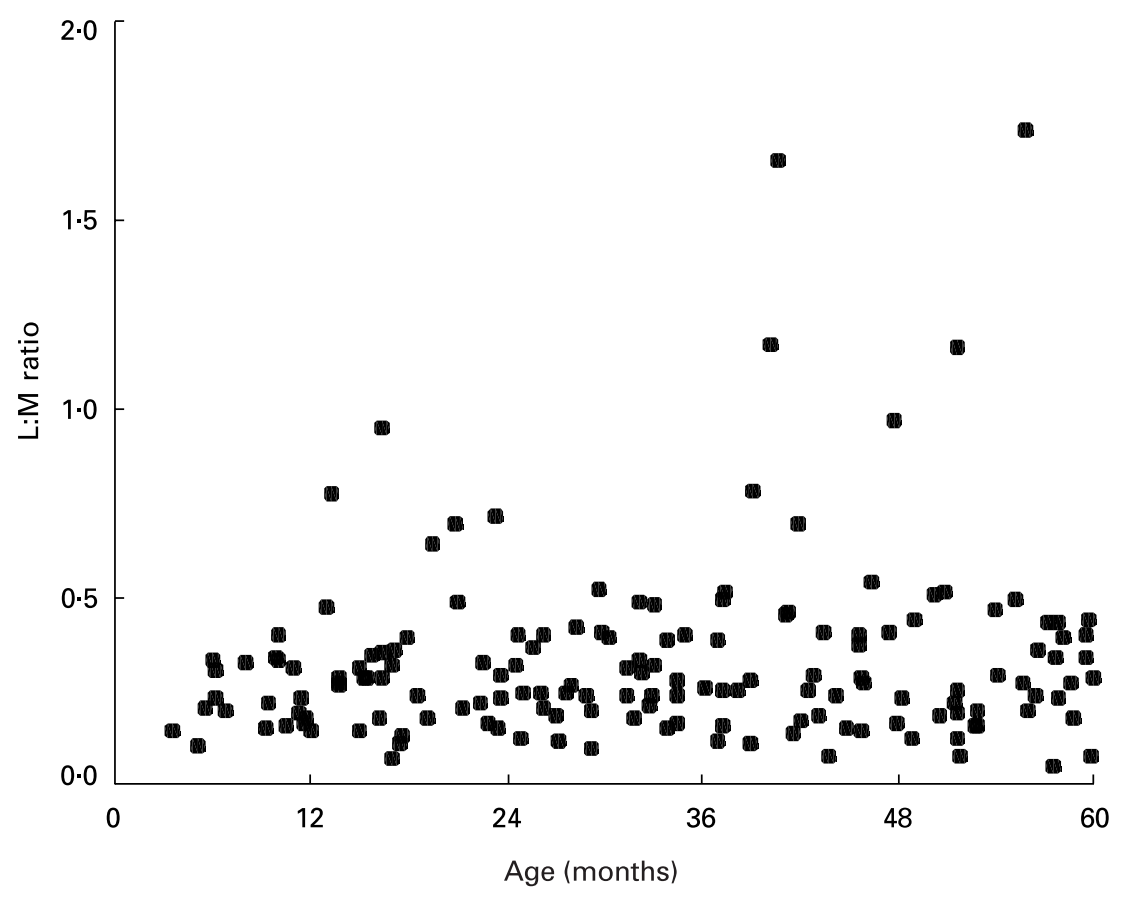

Fig. 2. Values of intestinal permeability in Nepali children ( $r 0.130, P=N S, n 158)$. L:M, lactulose:mannitol. For details of subjects and procedures, see Table 1 and pp. 142-143.

ratios (geometric mean 0.43 for Giardia-infected v. 0.25 for non-infected children), even though only eight children were infected with this protozoan (post-hoc tests, $P$ 0.014 for Giardia $v$. non-infected children; $P=0.03$ for Giardia $v$. helminth infections; NS for non-infected $v$. helminth infections; Fig. 3). Giardia infection per se also

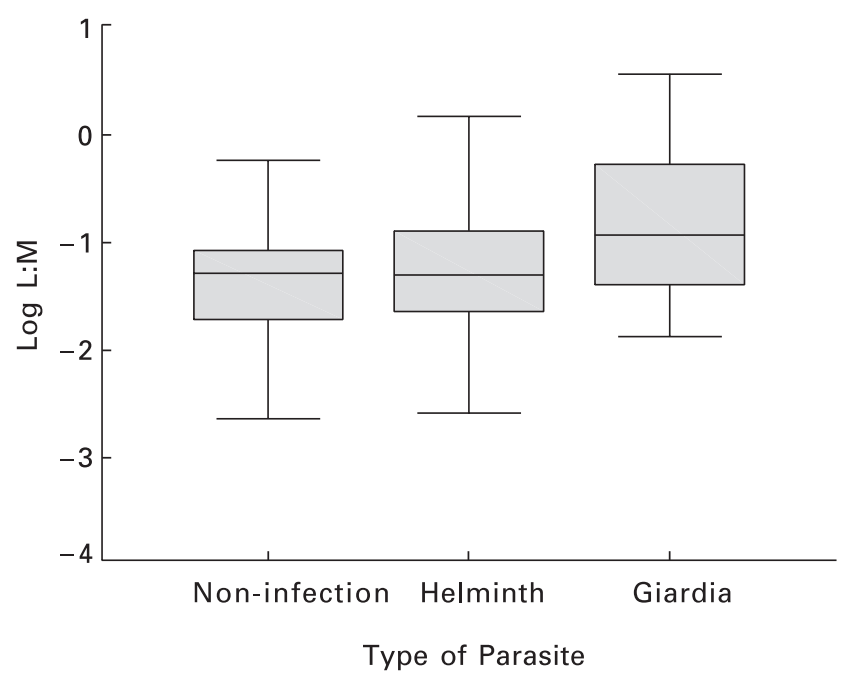

Fig. 3. Impact of parasite infection on intestinal permeability. L:M, lactulose:mannitol. Geometric means for L:M ratios are 0.43 for children with Giardia $(n 8)$ v. 0.25 for children with no infection $(n$ 45 ) and 0.27 for children with helminths $(n 73)$ (post-hoc tests, $P=0.014$ for Giardia $v$. non-infected children; $P=0.03$ for Giardia $v$. helminth infections; NS for non-infected $v$. helminth infections). For details of subjects and procedures, see Table 1 and pp. 142-143. Values are medians with the range shown by vertical bars and quartiles by shaded boxes. affected lactose $(P=0.009)$ and lactose:lactulose ratios $(P=0.02)$. It had no detectable impact on anthropometric measurements.

\section{Morbidity}

Of 172 children for whom morbidity data were available, forty-three were reported ill (40\% with diarrhoea) the previous day and seventy-one children were ill (32\% with diarrhoea) in the preceding $7 \mathrm{~d}$. Illness in the preceding $7 \mathrm{~d}$ was negatively associated with child age $\left(R^{2} 3 \%\right.$, $P=0.033$ ), and diarrhoea in the preceding $7 \mathrm{~d}$ associated with both age and ethnicity $\left(R^{2} 7 \%, P=0.010\right)$ : thus young children were more likely to be ill and TibetoBurmese children were more likely to have diarrhoea.

Illness in the previous day had no detectable impact on intestinal permeability ratios, but was associated with higher lactose values and also lactose:lactulose ratios $\left(R^{2}\right.$ $31 \%$ and $36 \%$ respectively, $P<0.0001$, controlling for infant age). Specifically, having diarrhoea was associated with higher lactose and lactose:lactulose values $(P<0.001)$.

\section{Weaning practices}

Only two out of 172 children were not breast-fed from birth. Children started supplementary weaning foods at 6 months (variable A, mean 5.9 (SD 3.9) months) and stopped breast-feeding when 2-years-old (variable B, mean 23.0 (SD 11.6) months). At the time of the study, the duration of supplementation was 27 months (variable B, mean 26.6 (SD 16.6) months), and the average time on solids was 19 months (variable D, mean 19.1 (SD 12.4) months). 
Table

3. Two stepwise regression analyses for intestinal permeability (log L:M ratio)*

\begin{tabular}{|c|c|c|c|c|}
\hline Independent variables† & $R^{2}$ & $\mathrm{~B}$ & SE & $P$ \\
\hline \multicolumn{5}{|l|}{ Stage 1. Breast-feeding group ( $n$ 44) } \\
\hline No variables & - & - & - & - \\
\hline \multicolumn{5}{|c|}{ Stage 2. Non-breast-feeding group ( $n 48)$} \\
\hline Weaning practice (variable C) $\ddagger$ & 0.095 & 0.017 & 0.008 & 0.031 \\
\hline
\end{tabular}

L:M, lactulose:mannitol; B, regression coefficient.

* For details of subjects and procedures, see Table 1 and pp. 142-143.

† Independent variables include infant age, weaning practices, parasite infection, morbidity and location.

$\ddagger$ Time until stopped breast-feeding.

Stage 1 of weaning (the onset of food supplementation) was associated positively with no other characteristic than child age $\left(R^{2} 95 \%, P<0.0001\right.$ for variable B). Stage 2 (the cessation of breast-feeding, variables $\mathrm{C}$ and $\mathrm{D}$ ) was associated with age and location (in the location easily flooded by river water, children stopped breast-feeding later) $\left(R^{2}\right.$ $41 \%, P<0.0001$ and $P=0.031$ respectively for variable C; $R^{2} 33 \%, P<0.0001$ and $P=0.018$ respectively for variable D). Sex, caste and ethnicity of the child had no detectable association with weaning practices.

Intestinal permeability was associated with stage 2 of weaning, but not stage 1: variable $\mathrm{C}$ accounted for $10 \%$ of the variance in L:M ratios $(P=0.031$; age, parasite infection, location, morbidity and variable $\mathrm{D}$ made no additional impact; Table 3). Fig. 4 illustrates the positive relationship between variable $\mathrm{C}$ and intestinal permeability. Children with a longer period of breast-feeding (more than 2 years) showed higher L:M ratios (i.e. worse gut function) than children who had breast-fed for less time. The period of time on solid only (variable D) made no independent contribution to the variance in L:M ratios.

With respect to lactose digestion, stage 1 of weaning (duration of supplementation, variable B) was negatively related to lactose values $(P<0.001)$ and lactose:lactulose ratios $(P<0.0001)$, but only in the breast-fed group of children.

With respect to growth (HAZ), in the group of breastfeeding children, the only variable of importance was

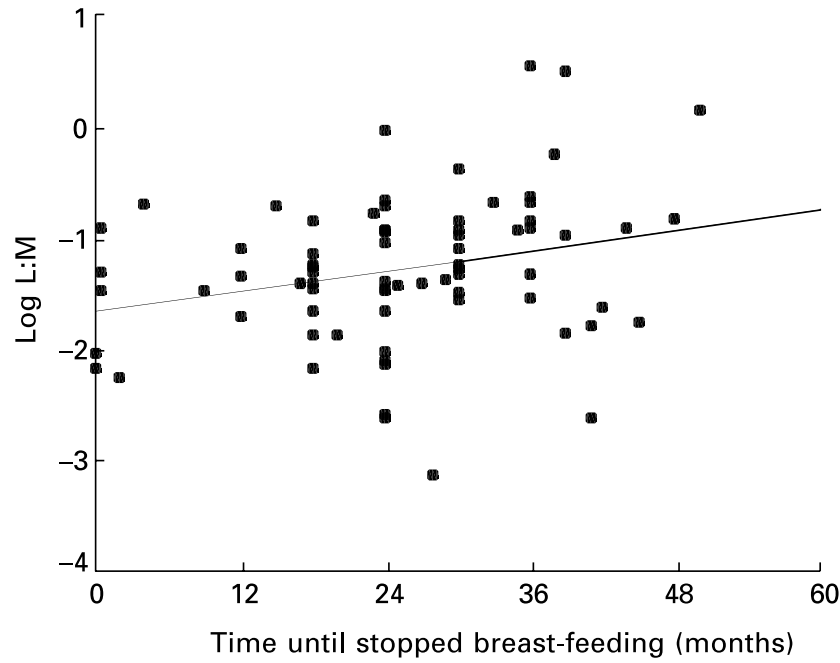

Fig. 4. The negative relationship between lactulose:mannitol (L:M) ratio (log values) and duration of breast-feeding (the time until stopped breast-feeding, variable C) $(r 0.271, P=0.019, n$ 75). For details of subjects and procedures, see Table 1 and pp. 142-143.

ethnicity and its interaction with age (Table 4). Among non-breast-feeding children, however, weaning stage 2 (variable $C$ ) had a strong negative impact on HAZ $(P=0.024)$; ethnicity had an impact on WAZ $(P=0.035)$ (Table 4). A longer period of breast-feeding was associated with poorer height-for-age; intestinal permeability ratio, lactose, parasite infection, location and reported morbidity had no detectable impact on growth status.

\section{Discussion}

The children in the present study were mildly stunted and underweight. Their growth status worsened rapidly, early in life (for 0-1-year-olds, mean HAZ -0.50 and WAZ -0.67 ; for $1-2$-year-olds, mean HAZ -1.51 and WAZ -1.51 ; post-hoc tests $P<0.0001)$. Tibeto-Burmese children fared better after 18 months of age, as reported in other studies (Martorell et al. 1994; Strickland \& Tuffrey, 1997).

Table 4. Two stepwise regression analyses for growth status (height-for-age and weight-for-age z-scores)*

\begin{tabular}{|c|c|c|c|c|c|c|}
\hline Independent variables† & Dependent variables & $n$ & $R^{2}$ & $\mathrm{~B}$ & SE & $P$ \\
\hline \multicolumn{7}{|l|}{ Breast-feeding group } \\
\hline & $\mathrm{HAZ}$ & 43 & 0.231 & & & \\
\hline Ethnicity & & & & 1.777 & 0.507 & 0.001 \\
\hline Ethnicity and age interaction & & & & 0.042 & 0.016 & 0.010 \\
\hline & WAZ & 44 & & & & \\
\hline No variables & & & & & & \\
\hline \multicolumn{7}{|l|}{ Non-breast-feeding group } \\
\hline & $\mathrm{HAZ}$ & 42 & $0 \cdot 113$ & & & \\
\hline Weaning variable $\mathrm{C} \ddagger$ & WIA7 & 18 & 0 & -0.026 & 0.011 & 0.024 \\
\hline Ethnicity & VVAL & 40 & 0.00 & 0.556 & 0.256 & 0.035 \\
\hline
\end{tabular}

HAZ, height-for-age z-score; WAZ, weight for-age z-score; B, regression coefficient.

${ }^{*}$ For details of subjects and procedures, see Table 1 and pp. 142-143.

†Independent variables included infant age, ethnicity, intestinal permeability, lactose, weaning practices, parasite infection,

morbidity and location.

‡Time until stopped breast-feeding 
As expected, the Nepali children showed poorer mucosal function than UK children (Table 2) (Lunn et al. 1991). The geometric mean of 0.26 for the Nepali children was very similar to that obtained for Bengali children who had been differentiated into subgroups of 'healthy' and 'ill with diarrhoea' individuals, with geometric mean values of 0.23 and 0.32 respectively (Rousham et al. 1998). Several studies support a strong relationship between a current episode of diarrhoea and poor gut function. In the Gambia, children who suffered from diarrhoea for more than $14 \mathrm{~d}$ showed significantly poorer intestinal permeability than children with diarrhoea for less than $14 \mathrm{~d}$ (geometric mean values 2.85 and 1.00 respectively, $P<0.001$; Behrens et al. 1987). In the present study, no significant differences were found in L:M ratio between children who had diarrhoea in the preceding $7 \mathrm{~d}$ and those who were reported to be healthy (geometric mean values 0.31 and 0.31 respectively). Other studies have simply excluded children affected with acute diarrhoea because of technical problems with urine collection (yet still found that recent history of diarrhoea was associated with altered gut function; Goto et al. 1999).

In the present study, neither reported morbidity nor helminth infestations were convincingly associated with altered intestinal permeability, or growth status. However, the presence of Giardia was significantly associated with poorer gut function $(P=0 \cdot 014)$. There were only a few identified cases of hookworm ( $n$ 8) and Giardia ( $n$ 8), which are the parasites that cause the greatest damage to the intestinal wall (Solomons, 1982; Farthing, 1984). Indeed, one recent study in Bangladesh reported a significant increase in the prevalence of Giardia intestinalis in a group of children treated with anthelmintics, which was associated with higher intestinal permeability and a shortterm reduction in weight (Lunn et al. 1998; NorthropClewes et al. 2001).

The timing of weaning also showed a significant impact on intestinal permeability. Interestingly, such impact was detected from the cessation of breast-feeding (stage 2) rather than from the introduction of supplementary foods (stage 1). To our knowledge, only one other study conducted in Guatemala (Goto et al. 1999) has specifically examined the associations between feeding practices and intestinal permeability. That study found that L:M ratios correlated with the age at termination of breast-feeding $(P=0.036)$, but were unrelated to the period of nonbreast-feeding. The authors argued that: 'it was the early termination of breast-feeding, rather than the amount of time since weaning that was associated most closely with altered small intestinal mucosal function', implicating, as in our current study, variable $C$ rather than variable $\mathrm{D}$.

However, Goto et al. (1999) reported a negative relationship (i.e. the early termination of breast-feeding worsened intestinal permeability values), while we found a positive one. The two studies, while both of poor peri-urban communities, are not entirely comparable, given the age of children included in the investigations. The Guatemalan children were $0-11$-months-old, and $28 \%$ ceased breastfeeding at 6-11 months of age; however, in Nepal, breast-feeding was terminated on average at 23 months. In sum, the Guatemalan children were weaned much earlier than the Nepali children, and the timing of weaning events may well differentially affect gut function. The Nepali sample included a large range of ages ( $0-5$ years). This includes both a precarious time of life with the introduction of weaning foods, at 3-6 months of age, and a more settled period after $12-15$ months of age, when growth can be expected to stabilise and gut permeability may not further worsen. It is possible that insults to the gut and challenges to the immune system have more of an impact on child health in the younger age group.

The present study found a clear association between gut function and weaning practices (the time until breast-feeding stopped) in Nepali children. However, the relationship is opposite to what might have been expected: children who were breast-fed for a longer period showed poorer intestinal permeability $(P=0 \cdot 031$, Table 3$)$. Such children also showed significantly poorer growth status $(P=0.024$, Table 4). These associations are not confounded by infant age or community location, and are not easy to explain. Field experience in Nepal suggests that Nepali mothers extend the nursing period for children whom they perceive are growing poorly. A cohort study in Guinea-Bissau, West Africa, similarly concluded that mothers who have malnourished children nurse for a longer time than mothers with better nourished ones (children with low weight-for-age were breast-fed longer that the better nourished children; Molbak et al. 1994). In addition, breast-feeding in older children may not have the expected protective effects on mucosal function; in Guatemala, Goto et al. (1999) suggested that breastfeeding prevents mucosal damage only in very young children, when the gut is very immature. The results suggest a complex association between life stage, the timing of weaning (cessation of breast-feeding), and the integrity of gut function in children. Those relationships may have an important differential impact on children's growth.

The Nepali children also showed high lactose excretion (47\% of them had lactose:lactulose ratios symptomatic of low lactase activity). Breast-fed children had significantly higher lactose values (and lactose:lactulose ratios) than those who were no longer breast-fed $(P<0.0001)$, but had similar intestinal permeability values. This probably reflects higher lactose intakes in those children still breast-feeding, which fall after stage 2 of weaning. Lactose values were also positively related to morbidity reported for the previous day $(P<0.0001)$, and particularly to diarrhoea $(P<0 \cdot 001)$. Such observations probably reflect gut damage and poorer lactose absorption concurrent with diarrhoea.

Finally, there was no direct association between gut function and growth status per se. Such results do not support the suggestion that gut damage is significantly associated with growth retardation in poor developing countries (Lunn, 2000). However, these negative results could be attributed to several factors. First, the present study is cross-sectional rather than longitudinal, which is an important limitation. Second, the urban poor Nepali children were only mildly stunted, with just $37 \%$ of children actually stunted in height. Third, observed intestinal permeability ratios showed a rather large range of raw values, which could not be explained by either morbidity or helminth 
infestation although it was related to Giardia and to weaning practices. Fourth, the children in this study were relatively old (mean age 45 months), so that the association between growth and intestinal permeability might not be clearly shown. By contrast, the studies in the Gambia focused on infants 3-15-months-old, a time of life when damage to the gut has its most significant effect on growth.

\section{Conclusions}

This study showed significant relationships between the timing of weaning practices and two variables, intestinal permeability and growth status (height-for-age), even though there was no direct association between intestinal permeability and stunting. A longer period of lactation was associated with poorer L:M ratios and height-for-age, suggesting that the expected protective effects of lactation on mucosal function do not extend to older children past early infancy. The study also found a significant association between Giardia infection and poor intestinal permeability, despite the small number of children affected by protozoa in the sample. These results suggest complex relationships between children's age, the timing of weaning events, and gut function leading to food malabsorption. In clearly differentiating between onset of food supplementation and breastfeeding cessation, the study highlights the differential impact of these two distinct stages of weaning on the health of children. In focusing on a population where breast-feeding lasts for about 2 years, it also draws attention to associations between the late cessation of breast-feeding, growth and gut function, for children past infancy.

\section{Acknowledgements}

This study was facilitated by affiliation with Tribhuvan University, Kathmandu, Nepal, and financial assistance from the Infant and Child Research Network (ICRN), University of Durham.

\section{References}

Almedom AM (1991) Infant feeding in urban low-income households in Ethiopia: Determinants of weaning. Ecology of Food and Nutrition 25, 111-121.

Behrens RH, Lunn PG, Northrop CA, Hanlon PW \& Neale G (1987) Factors affecting the integrity of the intestinal mucosa of Gambian children. American Journal of Clinical Nutrition 45, 1433-1441.

Blood J, Ingle AR, Allison N, Davies GR \& Hill PG (1991) Rapid enzymic method for the measurement of mannitol in urine. Annals of Clinical Biochemistry 28, 401-406.

Costello AM (1989) Growth velocity and stunting in rural Nepal. Archives of Disease in Childhood 64, 1478-1482.

Farthing MJ (1984) Giardiasis: pathogenesis of chronic diarrhea and impact on child growth and development. In Chronic Diarrhea in Children, pp. 253-267 [E Lebenthal, editor]. Vevey and New York, NY: Nestlé and Raven Press.

Gartoulla RP (1998) Therapy Pattern of Conventional Medicine with Other Alternative Medicines - a Study in Medical Anthropology in Nepal. Kathmandu: RECID/NEPAL.

Goto K, Chew F, Torun B, Peerson JM \& Brown KH (1999) Epidemiology of altered intestinal permeability to lactulose and mannitol in Guatemalan infants. Journal of Pediatric Gastroenterology and Nutrition 28, 282-290.

Hamill PW (1977) NCHS Growth Curves for Children, Birth-18 Months. Hyattsville, MD: National Center for Health Statistics, DHEW, (PHS), 78-1650.

Katz J, West KP Jr., LeClerq SC, Thapa MD, Khatry SK, Shresta SR, Pradhan EK \& Pohkrel RP (1998) Agreement between clinical examination and parental morbidity histories of four children in Nepal. Journal of Tropical Pediatrics 44, 225-229.

Kroeger A (1983) Health interview surveys in development countries: a review of the methods and results. International Journal of Epidemiology 12, 465-481.

Lohman TG, Roche AF \& Martorell R (1988) Anthropometric Standardization Reference Manual. Champaign, IL: Human Kinetics Books.

Lunn PG (2000) The impact of infection and nutrition on gut function and growth in childhood. Proceedings of the Nutrition Society 59, 147-154.

Lunn PG, Erinoso HO, Northrop-Clewes CA \& Boyce SA (1998) Giardia intestinalis is unlikely to be a major cause of the poor growth of rural Gambian infants. Journal of Nutrition 129, $872-877$.

Lunn PG, Northrop CA \& Northrop AJ (1989) Automated enzymatic assays for the determination of intestinal permeability probes in urine. 2. Mannitol. Clinica Chimica Acta 183, 163-170.

Lunn PG \& Northrop-Clewes CA (1992) Intestinal permeability: update on the enzymatic assay of mannitol. Clinica Chimica Acta 205, 151-152.

Lunn PG, Northrop-Clewes CA \& Downes RM (1991) Recent development in the nutritional management of diarrhoea, 2. Chronic diarrhoea and malnutrition in The Gambia: studies in intestinal permeability. Transactions of the Royal Society of Tropical Medicine and Hygiene 85, 8-11.

Martorell R, Kettek Khan L \& Schroeder DG (1994) Reversibility of stunting: epidemiological findings in children from developing countries. European Journal of Clinical Nutrition 48, Suppl. 1, S45-S57.

Moffat T (1998) Urbanization and child growth in Nepal. American Journal of Human Biology 10, 307-315.

Moffat T (2001) A biocultural investigatiom of the weanling's dilema in Kathmandu, Nepal: do universal recommendations for weaning practices make sense? Journal of Biosocial Science 33, 321-338.

Molbak K, Gottschau A, Aaby P, Hojlyng N, Ingholt L \& Da Silva APJ (1994) Prolonged breast feeding, diarrhoeal disease, and survival of children in Guinea-Bissau. British Medical Journal 308, 1403-1406.

Noone C, Menzies IS, Banatvala JE \& Scopes JW (1986) Intestinal permeability and lactose hydrolysis in human rotaviral gastroenteritis assessed simultaneously by non-invasive differential sugar permeation. European Journal of Clinical Investigation 16, 217-225.

Northrop CA, Lunn PG \& Behrens RH (1990) Automated enzymatic assays for the determination of intestinal permeability probes in urine. 1. Lactulose and lactose. Clinica Chimica Acta 187, 79-88.

Northrop-Clewes CA, Rousham EK, Mascie-Taylor CGN \& Lunn PG (2001) Anthelmintic treatment of rural Bangladeshi children: effects on host physiology, growth and biochemical status. American Journal of Clinical Nutrition 73, 53-60.

Northrop-Clewes CA, Lunn PG \& Downes RM (1997) Lactose maldigestion in breast-feeding Gambian infants. Journal of Pediatric Gastroenterology and Nutrition 24, 257-263.

Panter-Brick C (1992) Women's work and child nutrition: the food intake of 0-4 year old children in rural Nepal. Ecology of Food and Nutrition 29, 11-24.

Panter-Brick C (1997) Seasonal growth patterns in rural Nepali children. Annals of Human Biology 24, 1-8. 
Panter-Brick C (1998) Biological anthropology and child health: context, process and outcome. In Biosocial Perspective on Children, pp. 66-101 [C Panter-Brick, editor]. Cambridge: Cambridge University Press.

Panter-Brick C, Todd A \& Baker R (1996) Growth status of homeless Nepali boys: do they differ from rural and urban controls? Social Science and Medicine 43, 441-451.

Ross DA \& Vaughan JP (1986) Health interview surveys in developing countries: a methodological review. Studies in Family Planning 17, 78-94.

Rousham EK, Northrop-Clewes CA \& Lunn PG (1998) Maternal reports of child illness and the biochemical status of the child: the use of morbidity interviews in rural Bangladesh. British Journal of Nutrition 80, 451-456.
Solomons NW (1982) Giardias: nutritional implications. Reviews of Infectious Disease 4, 859-869.

Strickland SS \& Tuffrey VR (1997) Form and Function - a Study of Nutrition, Adaptation and Social Inequality in Three Gurung Villages of the Nepal Himalayas. London: Smith-Gordon and Company Ltd.

Tanner JM (1986) Use and abuse of growth standards. In Human Growth, 2nd edition, pp. 95-109 [F Falkner and JM Tanner, editors]. New York, NY: Plenum Press.

Ulijaszek SJ \& Kerr DA (1999) Anthropometric measurement error and the assessment of nutritional status. British Journal of Nutrition 82, 165-177.

United Nations Children's Fund (1996) Children and Women of Nepal - a Situation Analysis. Kathmandu, Nepal: UNICEF. 